\title{
Aprendizagem de inglês como segunda língua: análises à luz de teorias e modelos de aquisição de linguagem
}

\author{
Learning English as a second language: analysis according to the theories and \\ models of the language acquisition
}

\author{
Vânia Romancini Musachi ${ }^{1}$ \\ Universidade do Estado de Mato Grosso \\ Jislaine da Luz ${ }^{2}$ \\ Universidade do Estado de Mato Grosso \\ Sandra Borsari ${ }^{3}$ \\ Universidade do Estado de Mato Grosso \\ Juliana Freitag Schweikart ${ }^{4}$ \\ Universidade do Estado de Mato Grosso
}

\begin{abstract}
- RESUMO: com o advento da globalização a língua inglesa tem assumido o papel de uma língua global. Nessa perspectiva, a presente pesquisa visa analisar e sistematizar hipóteses, teorias e modelos de aquisição da linguagem presentes no processo de aquisição/aprendizagem de inglês como segunda língua. Segundo Vera Menezes de Oliveira e Paiva (2014), embora haja tantas teorias, hipóteses e métodos que tentam explicar a aquisição da linguagem, ainda não foi possível chegarmos a um consenso de como o ser humano aprende uma língua, pois em nenhuma das teorias podemos encontrar explicações concretas desse fenômeno. Utilizando-se de entrevista semiestruturada foram entrevistadas três pessoas que, no decorrer da pesquisa, relatam como aconteceu o processo de aquisição/aprendizagem da segunda língua e suas estratégias de aprendizagem. Os resultados obtidos através das análises é a presença não somente de um método, teoria ou hipóteses, mas um entrecruzamento de várias delas.
\end{abstract}

- PALAVRAS-CHAVE: Linguística Aplicada. Aprendizagem. Segunda Língua. Inglês. Teorias.

- ABSTRACT: with the advent of globalization the English language has assumed the paper of a global language. In this perspective, the present research aims to analyze and systematize hypotheses, theories and models of the language acquisition present in the process of acquisition / learning of English as a second language. According to Vera Menezes de Oliveira e Paiva (2014), although there are so many theories, hypotheses and methods that try to explain the acquisition of language, it has not yet been possible to reach a consensus on how human beings learn a language, because in none of the theories we can find concrete explanations of this phenomenon. Using a semi-structured interview, three people were interviewed who, during the research, report how happened the process of their second language acquisition/learning and learning strategies. The results obtained through the analysis are the presence not only of a method, theory or hypothesis, but a cross-linking of several of them.

- KEYWORDS: Applied Linguistics. Learning. Second Language. English. Theories.

\footnotetext{
${ }^{1}$ Mestranda pelo Programa de Pós-Graduação em Letras (PPG Letras) da Universidade do Estado de Mato Grosso (UNEMAT/Câmpus Sinop). E-mail: vania.ufmt@gmail.com.

${ }^{2}$ Mestranda pelo Programa de Pós-Graduação em Letras (PPG Letras) da Universidade do Estado de Mato Grosso (UNEMAT/Câmpus Sinop). E-mail: jislaine.luz.2015@gmail.com.

${ }^{3}$ Mestranda pelo Programa de Pós-Graduação em Letras (PPG Letras) da Universidade do Estado de Mato Grosso (UNEMAT/Câmpus Sinop). E-mail: sandraborsary59@gmail.com.

${ }^{4}$ Doutora em Estudos Linguísticos.. Professora da Universidade do Estado de Mato Grosso (campus de Sinop) e do Programa de Pós-Graduação em Letras. E-mail: julianafreitag@unemat.br.
} 


\section{Introdução}

Há diversas perspectivas sob as quais a aprendizagem de uma segunda língua (L2), neste contexto língua inglesa, tem sido observada. De acordo com Vera Lúcia Menezes de Oliveira e Paiva (2014) existem várias teorias, hipóteses e modelos de aquisição de segunda língua (ASL) que são extremamente influentes e necessárias, pois fornecem subsídios teóricos capaz de orientar a compreensão das abordagens e métodos utilizados no ensino/aprendizagem da L2.

Em seu livro Aquisição de segunda língua, Paiva (2014), apresenta em dez capítulos, teorias, hipóteses e métodos que tentam dar conta de explicar como uma língua é aprendida. No mundo contemporâneo, a globalização e o desenvolvimento tecnológico propiciaram ainda mais o contato dos sujeitos com a diversidade linguística, e a busca pelo aprendizado de L2 tem sido cada vez mais notória, seja por motivos profissionais ou pessoais.

Pode-se dizer que o inglês tem assumido o papel de uma língua global, pois de acordo com Crystal (2003) uma língua alcança o status de global quando ela é reconhecida em todos os países. Crystal (2003, p. 9) complementa essa ideia quando nos diz que "uma língua tem tradicionalmente tornado uma língua internacional por uma razão chefe: o poder das pessoas - especialmente os poderes políticos e militares"

Atualmente a língua inglesa tem sido utilizada no âmbito político, econômico e totalmente disseminada no mundo da internet e da tecnologia. Por essas razões e pelo fato de necessidade de se acompanhar um mundo em constante desenvolvimento, as pessoas têm buscado cada vez mais a aprendizagem do idioma. Em conformidade com Rajagopalan (2003, p. 65) "[a] língua estrangeira sempre representou prestígio. Quem domina uma língua estrangeira é admirado como pessoa culta e distinta".

Diante deste panorama, esta pesquisa visa à análise das respostas de uma entrevista realizada com três pessoas que passaram pelo processo de aquisição/aprendizagem da língua alvo, a fim de evidenciar algumas teorias, modelos e hipóteses presentes neste processo.

Utilizamos a nomenclatura aquisição/aprendizagem, pois para Krashen (1985, apud PAIVA, 2014, p. 30), em sua hipótese da aquisição-aprendizagem há duas formas de desenvolver a L2 sendo a aquisição assemelhada ao processo da criança aprendendo a língua materna, ou seja, de forma inconsciente, e a aprendizagem que seria a forma consciente, o saber sobre a língua.

\section{Metodologia}

Considerando a natureza das informações pretendidas, essa pesquisa é caracterizada como social qualitativa. Gil (2018, p. 26) define a "pesquisa social como o processo que, utilizando a metodologia científica, permite a obtenção de novos conhecimentos no campo da realidade social".

Ainda conforme Gaskell $(2015$, p. 65) que afirma que a entrevista qualitativa é uma metodologia muito utilizada e que ela nos "fornece os dados básicos para desenvolvimento e compreensão das relações entre os atores sociais e sua situação", além de sua finalidade ser "explorar os espectros de opiniões [...] sobre o assunto em questão"

\footnotetext{
${ }^{5}$ Minha tradução (A language has traditionally become an international language for one chief reason: the power of its people - especially political and military power).
} 
(GASKELL, 2015, p. 68) a coleta de dados para a produção deste artigo foi realizada através de entrevista semiestruturada, que propicia maior liberdade ao informante.

A entrevista foi realizada no mês de agosto de 2018, e foram escolhidas três pessoas que têm acesso à língua inglesa como L2, objetivando recolher dados de como e quando aconteceu a aquisição/aprendizagem da L2. Utiliza-se o termo segunda língua baseado em Crystal (2003 p. 4) que considera que uma "linguagem é frequentemente descrita com uma 'segunda língua' porque ela é vista como complementar para a língua mãe ou a primeira língua de uma pessoa ${ }^{6}$ ". Como ponto de partida foi realizada uma pergunta padrão para todos os participantes "Como foi seu processo de aquisição/aprendizagem da língua inglesa?".

Participaram da entrevista três pessoas do sexo feminino com as seguintes profissões: E1 - engenheira civil; E2 - professora de língua inglesa em escola de idiomas e E3 - administradora. As respostas das entrevistas foram registradas em áudio e, posteriormente, transcritas, sem marcas de oralidade, pela entrevistadora para serem analisadas e identificadas as possíveis teorias, hipóteses ou métodos presentes no processo de aquisição/aprendizagem da L2 das participantes.

Além da entrevista será realizada a análise dos dados com base em Vera Lúcia Menezes de Oliveira e Paiva (2014) e a contextualização bibliográfica, ancoradas em, David Crystal (2003), Kanavillil Rajagopalan (2003, 2013, 2015, 2017) Diógenes Cândido de Lima (2017), Karim Siebeneicher Brito (2013), Zygmunt Bauman (2005) e Kathryn Woodward (2014).

\section{O inglês e a globalização}

Vivemos em um contexto histórico de uma "globalização em marcha desenfreada" (RAJAGOPALAN, 2017, p. 239), momento em que o inglês tem se disseminado no mundo da economia, da política, da internet e também no mundo das pesquisas e, de acordo com Rajagopalan (2015, p. 17), a língua inglesa tem sido usada "como a língua de contato, de convívio e de veiculação das ideias".

Para Diógenes Cândido de Lima (2017) a língua inglesa, com a globalização, com os avanços das tecnologias e dos rompimentos das fronteiras linguísticas, tem tomado uma dimensão nunca vista antes na história das línguas. Portanto, a busca incessante pela aquisição/aprendizagem do idioma tem sido uma constante na vida das pessoas que anseiam fazer parte deste mundo globalizado. Em conformidade com esta ideia Rajagopalan (2003, p. 65) é enfático ao afirmar que "as pessoas se dedicam à tarefa de aprender línguas estrangeiras porque querem subir na vida".

Rajagopalan (2013, p. 158-159) acrescenta ainda que "[no] mundo globalizado em que vivemos, conhecer um pouco da língua inglesa significa ter melhores oportunidades de estudo e emprego". Corroborando com essa ideia, Brito (2013, p. 65) discorre que:

Os motivos que levam à aprendizagem de diversas línguas pelo indivíduo incluem enriquecimento pessoal, viagens, aperfeiçoamento educacional e vantagens econômicas. Esse tipo de multilinguismo é geralmente voluntário e planejado, em virtude da possibilidade de se adquirir vantagens, e é mais disseminado em países onde a língua nacional não detém amplo prestígio internacional.

\footnotetext{
${ }^{6}$ Minha tradução (A language is often described as a 'second language', because it is seen as a complement to a person's mother tongue, or 'first language').
} 
Acerca da expansão global da língua inglesa Crystal (2003) ainda é enfático ao afirmar que o inglês é a língua mais ensinada como uma língua estrangeira em mais de 100 países. De acordo com ele a expansão também se deve pela mobilidade das pessoas, tanto fisicamente quanto eletronicamente, pois atualmente tem tido um aumento significante o na tecnologia, e crescido o número de viagens pelo mundo. Para Crystal (2003, p. 14):

Não há precedentes na história da humanidade para o que acontece com as línguas, em circunstâncias tão rápidas de mudanças. Nunca houve um tempo quando tantas nações precisavam falar uma com a outra. Nunca houve um tempo quando as pessoas desejavam viajar para tantos lugares. Nunca houve um tempo de tantos recursos de tradução e interpretação em convenções. Nunca a necessidade de se espalhar o bilinguismo foi maior, para não sobrecarregar os poucos profissionais. E nunca houve com mais urgência a necessidade de uma língua global ${ }^{7}$.

Com a evidente expansão e dimensão que a língua inglesa tem tomado, Rajagopalan (2015) diz que Gáspari está com toda razão quando deixa a entender que nada indica que o papel do inglês será modificado. "Por conseguinte, a melhor opção que temos é tentar adquirir um domínio razoável sobre o idioma, para que não fiquemos atrás de milhões de chineses, japoneses, coreanos que estão investindo pesadamente na aprendizagem da língua". (RAJAGOPALAN, 2015, p. 18).

$\mathrm{Na}$ constante busca pela aquisição/aprendizagem da L2, o que entra em evidência é também a questão da identidade. Pois com as transformações advindas da globalização a nossa sociedade encontra-se em processo de mudanças, assim também nossas identidades passam por esse processo, abalando a ideia de um ser pronto e acabado. Neste sentido, Zygmunt Bauman (2005) usa os termos "líquido" e "fluído" para descrever o momento histórico que vivemos. Para Bauman (2005, p. 57):

Estamos agora passando da fase "sólida" da modernidade para a fase "fluida". E os "fluidos" são assim chamados porque não conseguem manter a forma por muito tempo e, a menos que sejam derramados num ambiente apertado, continuam mudando de forma sob a influência até mesmo das menores forças.

E assim são também as nossas identidades, "líquidas" e "fluídas", pois com a expansão da língua inglesa, a sociedade tem exigido constantes atualizações, o que nos leva a refletir que a identidade não é um atributo fixo, unificado, mas um fenômeno que acontece na relação com o mundo social. Kathryn Woodward (2014) no diz que as transformações e mudanças globais nas esferas sociais, econômicas, políticas e culturais colocam em evidência as questões de identidade.

Para Brito (2013, p. 63) "a língua que utilizamos nos dá um sentido de identidade". Neste sentido, Rajagopalan (2003, p. 69) evidencia que:

\footnotetext{
${ }^{7}$ Minha tradução (There are no precedents in human history for what happens to languages, in such circumstances of rapid change. There has never been a time when so many nations were needing to talk to each other so much. There has never been a time when so many people wished to travel to so many places. There has never been such a strain placed on the conventional resources of translating and interpreting. Never has the need for more widespread bilingualism been greater, to ease the burden placed on the professional few. And never has there been a more urgent need for a global language).
} 
[...] se torna cada vez mais urgente entender o processo de "ensinoaprendizagem' de uma língua "estrangeira" como parte integrante de um amplo processo de redefinição de identidades. Pois as línguas não são meros instrumentos de comunicação [...]. As línguas são a própria expressão das identidades de quem deles se apropria. Logo quem transita entre diversos idiomas está redefinindo sua própria identidade. Dito de outra forma quem aprende uma língua nova está se redefinindo como uma nova pessoa.

Portanto, o fenômeno da aquisição/aprendizagem da L2 é também uma experiência identitária, pois não se trata somente de um processo de acúmulo de informações linguísticas e culturais, mas de um processo de mudança e de transformação.

\section{Teorias, hipóteses e métodos de aquisição de segunda língua abordados por Paiva (2014)}

Segundo Paiva (2014), embora haja tantas teorias, hipóteses e métodos que tentam explicar a aquisição da linguagem, ainda não foi possível chegarmos a um consenso de como o ser humano aprende uma língua, pois em nenhuma das teorias podemos encontrar explicações concretas desse fenômeno.

Em seu livro Aquisição de segunda língua, Paiva (2014) estabelece diálogos de narrativas de aquisição/aprendizagem de L2 com várias teorias e métodos que propiciam esse processo. Dessa forma Paiva dedica nove capítulos a cada teoria, sendo elas: teoria behaviorista-estrutural; modelo monitor, hipótese do input ou da compreensão; modelo da aculturação; modelo da gramática universal; modelo conexionista; hipótese de interação; hipótese do output ou da lingualização; teoria sociocultural e aquisição de segunda língua na perspectiva da complexidade.

Para finalizar sua obra acrescenta no décimo capítulo um resumo de outras quinze teorias, sendo elas: modelo $\mathrm{ACT}^{*}$, teoria de processamento da informação, teoria funcional-tipológica, abordagem orientada para o conceito, modelo de competição, teoria neurofuncional, teoria da interlíngua, modelo cognitivo-interacionista, modelo da competência variável, modelo multidimensional, teoria CREED associativo-cognitiva, tória da acomodação, abordagem da identidade, teoria da atividade e o modelo dialógico.

Diante de um vasto campo de teorias, hipóteses e métodos, e das narrativas obtidas através das entrevistas realizadas para essa pesquisa, foi possível detectar vários desses modelos. Para tanto, na análise dos dados, trarei um pouco de cada teoria evidenciada nas narrativas. Seria possível identificar outros modelos, hipóteses e teorias, mas as destacadas na análise foram: o modelo monitor, hipótese do input ou da compreensão; teoria da acomodação; modelo da aculturação; hipótese da interação; teoria sociocultural e a teoria do behaviorismo de Skinner.

\section{Análise dos dados}

E1: meu pai me colocou na escolinha de inglês particular e fui conciliado, tinha facilidade na escola por conta do cursinho de inglês fora o que na escola era muito básico então para mim era muito fácil o inglês da escola.

(1) E3: O primeiro contato que eu tive com a língua inglesa foi na escola no primário, depois ensino médio [....] mas eram coisas assim bem simples porque a metodologia, o 
inglês aprendido na escola junto com as outras disciplinas ele é um pouco mais restrito do que o inglês que você aprende especificamente numa escola de idiomas.

Nos excertos (1) e (2) das narrativas de aprendizagem de língua inglesa foi possível observar evidências dos princípios de Krashen (1981, apud PAIVA, 2014, p. 29) que propõe que a aprendizagem em L2 deva ser similar à aprendizagem da primeira língua (L1), para isto deveriam ser feitos esforços para criar ambientes em salas de aula de L2 que se aproximassem das condições da aquisição de L1.

(3) E1: como eu entrei muito nova a maior parte dos meus colegas era muito mais velhos, eu sempre tive vergonha de falar e errar e tirarem sarro. Enfim deu para perceber que eu não aproveitei o meu ensino tanto quanto eu poderia ter aproveitado então eu acabei criando uma birra de ir para a escolinha de inglês e de aprender porque tinha muita dificuldade.

(4) E2: O meu primeiro contato com o idioma foi assistindo filme assistindo série ouvindo música algo que eu sempre gostei muito e por conta disso eu escutava música e eu ia pesquisar o lecture da música tipo a letra para poder cantar junto eu via alguma expression em algum filme e eu pesquisava para saber em que situação eu poderia usar então isso me ajudou muito no aprendizado.

(5) E2: quando eu comecei a estudar por livros, eu ficava muito entediada porque parecia que nunca saia do lugar então sempre procurei pesquisar as coisas por conta própria.

(6) E3: no final do segundo grau já no início da graduação eu fui para uma escola de idiomas porque eu queria aprender mesmo a língua inglesa não como uma disciplina obrigatória da grade da escola, mas como algo para o mercado de trabalho, pra poder viajar pra fora.

(7) E3: meu interesse na língua inglesa além do campo profissional despertou bastante depois que eu fui viajar para o país que fala o idioma.

Nas narrativas (3), (4), (5), (6) e (7) é possível identificar a hipótese do filtro afetivo de Krashen (1985) que define filtro afetivo como um bloqueio mental que impede os aprendizes de utilizar plenamente o input recebido. Na E1 o filtro afetivo se encontra alto, bloqueando o input compreensível, já na E2 e E3, o filtro afetivo está baixo, a aprendiz está motivada, e se vê como membro futuro da comunidade de falantes da língua inglesa. Outra teoria visível nas narrativas E2 e E3 é a Teoria da Acomodação, proposta por Gilles (1973) que chama a atenção para os papéis das atitudes sociopsicológicas e motivação, sendo que o nível da motivação é um fator determinante na proficiência em L2.

(8) E1: quando eu entrei no ensino médio fui fazer intercambio, morei seis meses no Canadá e foi ai que eu aprendi inglês na marra porque tinha que falar para se comunicar para pedir as coisas se não, não conseguia viver, e foi onde eu aprendi.

(9) E1: no Canadá eu morava com duas crianças pequenas, na época uma delas tinha 4 anos ela assistia muito desenho infantil e era muito fácil para eu entender o desenho. Foi onde eu percebi que era a maneira mais fácil de eu aprender, se eu assistisse um seriado um 
filme, como tem uma linguagem mais formal era mais difícil e quando eu assistia com ela os desenhos eu entendia tudo. Foi ai que eu aprendi que existiam meios mais fáceis de aprender o inglês e foi assim que eu aprendi com mais facilidade, eu ajudava ela nas tarefas e ela estava sendo alfabetizada, como alfabetizam as crianças aqui. Muita coisa eu aprendi estudando junto com ela, eles aprendem pela fonética das letras e foi assim que eu comecei a aprender como pronunciar muitas palavras. $\mathrm{O}$ que mais me ajudou foi esse contato com as crianças.

(10) E1: ano passado eu fui para o Canadá novamente, mas fiquei apenas três semanas lá fazendo um curso de inglês para estrangeiros. Chegando lá fiz o nivelamento o meu nível foi um nível muito bom eu entrei no nível 11 ou 12 não me recordo e vai até o nível 15 , então foi bem satisfatório. Infelizmente pelo tempo que eu fiquei eu não consegui subir de nível não foi o suficiente pra eu melhorar meu desempenho, mas se eu tivesse ficado talvez mais um ou dois meses, eu conseguiria passar provavelmente para o nível superior.

Nos excertos (8), (9) e (10), da entrevistada E1, é facilmente identificada o modelo da aculturação proposto por Schumann que afirma que, diferentemente de outras disciplinas escolares é possível aprender uma língua de forma natural, ou seja, em contato com seus falantes. Schumann $\left(1978^{a}\right.$, p. 28 apud PAIVA, 2014, p. 51) "lista uma série de fatores que influenciam a aquisição e os agrupam em nove grupos: social, afetivo, personalidade, cognitivo, biológico, aptidão, pessoal, instrucional e insumo linguístico".

Para ele, os dois mais importantes são o social e o afetivo, que ele propõe unir em uma categoria única por ele denominada de aculturação e que define como "a integração social e psicológica do aprendiz com o grupo da língua alvo" (SCHUMANN 1978a, p. 28 apud PAIVA, 2014, p. 51).

Juntamente com a aculturação é possível observar a Hipótese da Interação, proposta por Hatch (1978) que afirma que o discurso é a origem da aquisição da segunda língua e levanta a hipótese de que a aquisição não parte da estrutura para o discurso, mas o contrário: "Aprende-se como conversar, como interagir verbalmente, e dessa interação se desenvolvem as estruturas sintáticas" (HATCH, 1978, p. 404 apud PAIVA, 2014, p. 99). Para ela o aprendiz de segunda língua utiliza estratégias semelhantes à da criança aprendendo a primeira língua.

(11) E1: depois que eu cheguei ao Brasil eu comecei a ir atrás, buscar. Comecei a ter interesse em ler livros em inglês, de olhar sites, de assistir filmes sem a legenda em português, ai eu comecei a me interessar. Depois eu me formei no cursinho de inglês, passei a trabalhar em uma escola de inglês então continuava em contato.

(12) E2: Eu sempre gostei de música então eu indico muito para os meus alunos escutarem música que eu acho que ajuda muito no aprendizado porque se você escuta bem você tem um bom listening você consegue entender o que a pessoa está falando, sua fala vai ser muito melhor, vai ser mais completa e você vai conseguir falar com velocidade.

Analisando as narrativas (11) e (12), nota-se a presença da teoria sociocultural que tem como precursor Vygotsky. De acordo com Lantolf e Beckett (2009, p. 459 apud PAIVA, 2014, p. 127) a denominação sociocultural aborda a ideia deque "o funcionamento mental humano resulta da participação em e da apropriação de formas de mediação cultural integradas em atividades sociais". Deste ponto de vista, temos os livros, os filmes, as músicas, como artefatos mediadores para o processo de aquisição/aprendizagem da L2. 
(13) E1: ela fazia a gente ler textos quando a gente lia algo errado ela voltava e ensinava a pronúncia e fazia a gente ficar repetindo e repetindo e repetindo até acertar a pronúncia. Falava igual se fala com criança. Quando a gente falava errado ela ia lá e pronunciava sílaba por sílaba até a gente conseguir a pronúncia correta ela não deixava a gente parar de repetir se não tivesse alcançado a pronúncia correta, principalmente daquelas palavras que são bem próximas que você diferencia pela fonética correta. Ela pegava bastante no pé por causa disso e foi interessante porque estava todo mundo ali disposto a aprender. A colaboração dos colegas também foi extremamente importante porque você via que ninguém tirava sarro, as pessoas, bem pelo contrário, eles queriam te ajudar.

No fragmento (13) da narrativa de E1, identificamos a teoria do behaviorismo, sendo Skinner um dos nomes mais lembrando quando se fala do ensino de línguas e behaviorismo. Skinner (1992, p. 14, apud PAIVA, 2014, p. 14)) define comportamento verbal como "um comportamento reforçado pela mediação de outra pessoa", e diz que "em todo comportamento verbal, há três eventos importantes a serem considerados: um estímulo, uma resposta e um reforço". A aprendizagem para Skinner é fruto de condicionamento operante, ou seja, um comportamento é reforçado até que ele seja condicionado de tal forma que, ao se retirar o reforço, o comportamento continue a acontecer.

\section{Considerações Finais}

Nos últimos tempos temos testemunhado a grande presença da língua inglesa em nosso cotidiano, neste sentido Rajagopalan (2003, p. 57) é enfático ao dizer: "queiramos ou não, vivemos num mundo globalizado. Entre outras coisas, isso significa que os destinos dos diferentes povos que habitam a terra se encontram cada vez mais interligados e imbricados uns nos outros".

É possível percebermos as constantes mudanças e transformações que advém dessa globalização, o que tem tornado a língua inglesa conhecida mundialmente, denominada por Crystal (2013) como uma língua global. Diante desse cenário é inegável a necessidade da aquisição/aprendizagem da língua alvo como L2, ou língua estrangeira, pelos indivíduos que querem fazer parte, integralmente, dessa globalização.

Para tanto, muitos indivíduos têm buscado a aquisição/aprendizagem da língua global, e durante este processo, é possível analisar, baseados em teorias, hipóteses e métodos de aprendizagem, como ocorre o processo de aquisição/aprendizagem de uma língua, neste caso específico da língua inglesa.

Como apresentado neste artigo, várias são os modelos, hipóteses e teorias que Paiva (2014) abordou em sua obra. E como já afirmado por Paiva (2014) que ainda não se é possível apontar com precisão como o indivíduo adquire uma segunda língua, diante desta pesquisa é notório que as teorias, os métodos e as hipóteses se complementam, pois cada uma delas capta aspectos diferentes de um mesmo fenômeno, sendo que algumas se ocupam mais dos aspectos linguísticos, outras do cognitivo e outras do social, sendo que o processo de aquisição/aprendizagem da L2 passa, necessariamente, pelo aprendiz.

\section{REFERÊNCIAS}


BAUMAN, Z. Identidade Entrevista Beneditto Vechi. Tradução de Carlos Alberto Medeiros. Rio de Janeiro: Jorge Zahar, 2005.

BRITO, Karim Siebeneicher. A promoção da competência multilíngue na escola: encorajando possibilidades. Calidoscópio. São Leopoldo, v. 11, n. 1, p. 63-69, jan./abr. 2013.

CRYSTAL, David. English as a Global Language. 2. ed. Cambridge: University Press, 2013.

GASKELL, George. Entrevistas individuais e grupais. In: BAUER, M. W.; GASKELL, G. (Orgs.). Pesquisa qualitativa com texto imagem e som - um manual prático. 2. ed. Petrópolis: Vozes, 2017. p. 64-89

GIL, Antônio Carlos. Métodos e Técnicas de Pesquisa Social. 6. ed. São Paulo: Atlas, 2018.

LIMA, Diógenes Cândido de. Anglicismo: como é tratado esse fenômeno na sala de aula de língua inglesa? In: LIMA, Diógenes Cândido de. (Org.). Ensino de Língua Inglesa: conversas com professores da escola pública. Campinas, SP: Pontes Editores, 2017. p. 259276.

PAIVA, Vera Lúcia Menezes de Oliveira e. Aquisição de segunda língua. 1. ed. São Paulo: Parábola Editorial, 2014.

RAJAGOPALAN, K. Por uma linguística crítica: linguagem, identidade e a questão ética. São Paulo: Parábola Editorial, 2003.

O ensino de línguas como parte da macro-política linguística. In: GERHARDT, Ana Flávia L. M; AMORIM, Marcel A.; CARVALHO, Álvaro M. (Orgs.). Linguística Aplicada e Ensino: Língua e Literatura. Campinas, SP: Pontes Editores, 2013.

Políticas Públicas, Línguas Estrangeiras e Globalização: a universidade brasileira em foco. In: ROCHA, C. H; BRAGA, D. B.; CALDAS, R. R. (Orgs.). Políticas Linguísticas, ensino de línguas e formação docente: desafios em tempos de globalização e internacionalização. Campinas: Pontes Editores, 2015. p. 15-27.

; CRAVALHO, Volnei M. A expansão do inglês e o desafio de ensiná-lo. In: LIMA, Diógenes Cândido de. (Org.). Ensino de Língua Inglesa: conversas com professores da escola pública. Campinas: Pontes Editores, 2017. p. 239-258.

WOODWARD, Kathryn. Identidade e diferença: uma introdução teórica e conceitual. In: SILVA, Tomaz Tadeu da (Org.). Identidade e Diferença. 15. ed. Petrópolis: Vozes, 2014. p. 7-72.

Recebido em: fevereiro de 2019. Aprovado em: maio de 2019.

Como citar este trabalho:

MUSACHI, V. R.; DA LUZ, J.; BORSARI, S.; SCHWEIKART, J. F. Aprendizagem de inglês como segunda língua: análises à luz de teorias e modelos de aquisição de linguagem. Traços de Linguagem. V.3, n.1, p. 89-97, 2019. 